\title{
Furthering the Internalization Debate: Gal'perin's Contribution
}

\author{
Igor Arievitch, René van der Veer \\ University of Leiden, The Netherlands
}

\section{Key Words}

Dualism · Gal'perin - Internalization - Mental action - Sociocultural psychology

\section{Abstract}

In this article we examine the contribution to the analysis of the problem of internalization made by the Russian psychologist Gal'perin. The concept of internalization has been criticized recently for restricting researchers to an old paradigm of Cartesian dualism, with the suggestion made that clearer concepts such as mastery or appropriation be substituted. In our view, the concept of internalization has the advantage of pointing to a specifically human type of appropriation. We propose an alternative solution. Rather than replacing one term with another, the very notions of internal and external in the realm of mental activity should be reconceptualized. In the framework of Gal'perin's ideas, the processes underlying the internalization concept can be construed without creating dualistic confusion. The result is a better understanding of the specificity of human mental development.

The concept of internalization is now undergoing thorough scrutiny within the sociocultural approach in developmental psychology. Due to the increasing number of Vygotsky-inspired studies, this basic concept has been the object of much critical reflection. Paradoxically, in recent publications [Lave and Wenger, 1991; Rogoff, 1990; Still and Costall, 1991], it has been regarded as an obstacle to fulfilling the task for which it was initially intended - to bridge the gap between internal and external, as well as between social and individual, in the conception of human development. The discussion has arrived at a new level of conceptual and historical analysis in Lawrence and Valsiner's [1993] article in this journal and Wertsch's [1993] commentary on it. In contrast to extreme sociological and individual-psychological reductionist solutions, Lawrence and Valsiner introduced a more balanced view of internalization as constructive transformation (rather than simple transmission) from social to personal experience. They claimed it necessary to go beyond general declarations that psychological development is socially constituted and specify in what ways the process of 'inter-to-intra' transformations take 
place. In his commentary, Wertsch largely agreed with Lawrence and Valsiner but raised the even more fundamental issue of whether the concept of internalization is useful at all.

In this article we intend to contribute to this debate by introducing a Gal'perian perspective on the problem of internalization. Gal'perin's approach is quite relevant to the search for answers to the two questions that have been the focus of recent debate: What exactly are the processes underlying internalization, and is the internalization concept adequate in principle? We concentrate mostly, however, on the latter question. We believe that the concept of internalization reflects important features of human mental functioning and that useful guidelines to reveal these features can be found in Gal'perin's theory. In the first part of this article we briefly outline the development of the internalization concept within the sociocultural approach and then discuss factors that have led some scholars to propose that the internalization concept be discarded and the difficulties doing so could create. To deal with these difficulties, in the second part of the article we turn to Gal'perin's ideas and discuss the way he reconceptualized the relation between external and internal processes through his analyis of the externality of mental activity and the different types of actions. This analysis allows us to clarify the specific character of the internal plane of action in humans - a plane that should not be overlooked whether the relevant process is referred to as internalization or another term.

The concept of internalization came into psychology along with the idea of the social origin of the human mind [Lawrence and Valsiner, 1993; Ratner, 1991]. It was meant to clarify the process of individual enculturation in the course of ontogenetic development. In the works of Baldwin [1911], Janet [1935], and Mead [1934], as well as in anthropological writings by Lévy-Bruhl [1922] and Durkheim [1912/1985], strong arguments were made that the starting point of human mental development lies not 'inside' but outside the individual and that individual mental processes originate from social activity. Many of these arguments became incorporated in Vygotsky's 'contextual' [Tudge and Winterhoff, 1993] sociocultural approach. Others were elaborated in the more 'individual-centered' theories of Piaget and others [Aronfreed, 1968; Bandura, 1986; Bühler, 1930; Piaget, 1974] which we do not consider here.

Vygotsky made the next step in this direction by elaborating on what kind of social material is 'transported' from the social into the intra-individual domain - the specific structure of human interaction, mediated by cultural tools, among which language is the most powerful [Luria, 1979; van der Veer and Valsiner, 1991a, 1994; Vygotsky, 1930/ 1981,1978 ]. According to Vygotsky, internalization can be conceived of as the ingrowing of signs into the individual's mental processes. The individual begins by using signs to organize the activity of other people and ends up making use of signs to restructure his or her own mental activity. This process leads to radical transformations in all psychic functioning, which becomes voluntary due to cultural mediation and the formation of a unique hierarchical makeup of consciousness.

In the works of Leont'ev [1959/1981] and the so-called Kharkov school [Cole, 1979-1980; Kozulin, 1986; Wertsch, 1981], research into the problem of internalization continued. The focus, however, shifted from the internalization of the mediated structure of social interaction to the transformation of external object-related meaningful activity into internal, mental forms of activity. Abundant experimental evidence of the intrinsic dependence of mental performance on the particularities of the subject's external activity was obtained [Leont'ev, 1959/1981]. To overcome the dualistic paradigm, it was emphasized that there is continuity between external (material) and internal (mental) activity and that their basic structures are identical. Leont'ev maintained that 
er but raised useful at all. Gal'perian e relevant to cent debate: lization conquestion. We uman mental be found in elopment of scuss factors iscarded and cond part of zed the relaxternality of o clarify the nould not be nother term. ea of the soIt was meant tic develops well as in strong argu$s$ not 'inside' m social acctual' [Tudge e more "indi986; Bühler,

kind of social the specific iguage is the gotsky, 1930/ he ingrowing g signs to oructure his or sychic funcmation of a

chool [Cole, ternalization diated struceaningful acice of the inct's external digm, it was nal (mental) at the process of internalization is not the transferral of an external activity to a preexisting, internal 'plane of consciousness': it is the process in which this internal plane is formed [1959/1981, p. 163. emphasis added].

Therefore, more explicitly than in Vygotsky's account of internalization, the very existence of something 'internal' before the acquisition of social and cultural experience was questioned in Leont'ev's writings. As we show, this line of reasoning, which is directly relevant to our topic, was continued by Gal'perin. But in the works of Leont'ev it was not further elaborated theoretically or experimentally. In his later research, Leont'ev primarily concentrated on the analysis of the components of activity as being in different relations to its motive. These distinctions became the hallmark of his socalled activity theory [Davydov, 1993; Engeström, 1991; Leont'ev, 1978].

The two basic meanings of internalization were thus: (a) the reproduction of the social inter-activities within the intra-individual domain, where they change the form of their functioning without changing their nature, i.e., remaining sociocultural and interactive (the dimension 'from social to individual' that was one of Vygotsky's basic concerns) and (b) the development of meaningful external, material activity into concrete 'internal', mental forms of the same activity. The latter is the dimension of internalization 'from external to internal' that became the focus of Leont'ev's and most of the Kharkov scholars' work.

In brief, the sociogenetic [van der Veer and Valsiner, 1991b] account of the concept of internalization implied several important ideas for developmental psychology. These were: (a) the sacial origin of human mind (Baldwin, Janet, Claparede); (b) the specific nature of human mental processes mediated by cultural tools (the Vygotskyan tradition), and (c) mental processes as kinds of activities and the notion of interdependence between internal and external activity (Janet, Mead, Leont'ev and his collaborators). Thus, the sociogenetic account of internalization essentially contributed to playing down the accounts of the primordial internal nature of the mind.

But paradoxically enough, the concept of internalization has recently come under strong critical analysis from a more 'radical' stance [Lave and Wenger, 1991; Lemke, 1990; Newman et al., 1989; Rogoff, 1990; Shotter, 1993a,b; Still and Costall, 1991; Wertsch, 1993]. It is regarded as implicitly grounded in some old Cartesian dualism between mind and body, in the form of a dualism between something external (and material) and something internal (mental rather than material). The following quotation from Wertsch [1993] is most characteristic in this respect:

Is the notion of internalization, in any of its guises. really useful? I believe we needed to raise this question because by invoking the notion of internalization we incorporate some theoretical bag. gage that can be very problematic. In particular, claims about internalization usually presuppose, and hence reinforce, a kind of dualism between the external and the internal - a dualism we often reject when it is made explicit, but one that nevertheless continues to lead us down blind alleys. Witness, for example, the search for internal copies of external patterns of action and the seemingly unending quest to locate more and more processes, structures, attributes, and so forth inside the individual [p. 168, italics in original].

We understand the concern expressed by Wertsch. but we suggest a somewhat different answer to his initial question. Indeed. the notion of internalization can be quite misleading. If understood in a certain way. it evokes the images of a 'spatial' transportation or transmission of some external material inside the individual brain. A related connotation is that of some material activity that gradually becomes ideal' or nonmaterial as the result of some process. These powerful (and common) images do reinforce im- 
plicit commitments to a Cartesian dualism [Markovà, 1982; Markovà and Foppa, 1990; Tolman, 1992; Wertsch and Stone 1985]. In turn, such commitments engender two illusions that have pervaded psychology ever since its inception. The first is that mental processes exist within the individual and, moreover, that it is possible to construct an account of the human mind and its development that starts with the isolated individual [Bruner, 1990; Harré, 1983, 1992; Wertsch, 1993]. The second illusion is that some internal 'space' (such as on computer disks) preexists where ready-made mental processes such as memory are stored and begin to unfold if necessary. Given these possible connotations, there are serious reasons to reassess the concept of internalization. These connotations and associated illusions suggest the desirability of substituting a more neutral term such as mastery, which retains the basic meaning without taking on the additional theoretical commitments (and burdens) associated with internalization [Rogoff, 1990; Wertsch, 1991].

To corroborate their positions regarding internalization, both Wertsch [1993] and Rogoff [1990] appeal to the same passage from Leont'ev that we have already quoted. But Leont'ev, clearly, does not reject the concept of internalization, he merely suggests it be interpreted in a certain way. Is this fact not evidence that Wertsch and Rogoff, while suggesting we discard the concept of internalization, nevertheless tacitly assume that it could be retained but in a version that does not imply the notion of spatially bringing something inside from outside? The point we wish to make is that simply replacing internalization with some other term may prove a difficult task (although, perhaps, desirable in the long run) and that it is worth further consideration before doing so. Even if we eventually replace internalization with another term - one that avoids its undesirable connotations while retaining the important ones - such analysis is necessary to insure that we do not lose any of the latter. Specifically, we believe that the concept of internalization has the advantage that it points to the human type of appropriation or mastery.

Appropriation and mastery mostly refer to the general process of the acquisition of new experience. If we do not deny the fact that animals learn and gain experience, some kind of appropriation also occurs in animals. But the concept of internalization was never intended to be applied to animals. In fact, from the very beginnings of the sociocultural approach, the concept of internalization was meant to emphasize features specific to human mental development [Cole, 1979-1980; Gal'perin, 1977/1992; Janet, 1928; Leont'ev, 1959/1981; van der Veer and Valsiner, 1991a,b; Vygotsky and Luria, 1930/1993; Wertsch, 1985; Wertsch and Stone, 1985]. Both of the basic dimensions of internalization mentioned earlier - social to individual and external to internal - refer only to human development and knowledge acquisition.

As a consequence, all of its undesirable connotations notwithstanding, the concept of internalization carries the very important meaning not just of learning something new, but of creating a specific realm of action - the 'internal plane of consciousness' that yields additional possibilities for adaptation. In other words, internalization is a specifically human, cultural form of knowledge acquisition. If we get rid of it without reflecting on all of its implications, we may lose sight of the specificity of human mental development. In our view, in order to avoid the external-internal dichotomy (and the associated pitfalls of Cartesian dualism), we should reconceptualize the internalization concept in the context of a revision of the more general notions of internal and external in mental development. In what follows, we present one of the possible ways to accomplish this objective expounded in the works of the Russian psychologist Gal'perin [1957/1989, 1965. 1967, 1978/1992]. Interestingly enough, Gal'perin's figure has been missing in the 
Foppa, 1990; der two illu- mental prostruct an acd individual some interal processes sible connoThese connore neutral he additional Rogoff, 1990;

h [1993] and eady quoted. ly suggests it Rogoff, while sume that it ally bringing bly replacing perhaps, deg so. Even if undesirable ry to insure t of internalor mastery. cquisition of rience, some lization was of the sociofeatures speJanet, 1928; a, 1930/1993; ernalization ly to human

the concept something pusness' that is a specifiut reflecting tal develope associated concept in al in mental omplish this [1957/1989. issing in the

current debate so far, although his contribution is potentially relevant as he spent a good deal of his career working on the issue of internalization and had something important to add in this respect.

\section{Gal'perin's General Position}

Piotr Gal'perin (1902-1988) was a contemporary of Vygotsky, Luria, and Leont'ev, with whom he shared many of the basic assumptions of cultural-historical psychology [van der Veer and Valsiner, 1991a; Van Geert, 1987]. Gal'perin, however, went much further in the concrete demonstration of how the specifically human plane of psychic activity, the internal plane of consciousness, is formed. To elucidate his view on internalization, we first need to point out that Gal'perin $(1965,1967)$ distinguished between two levels of analysis of the individual's enculturation processes related to internalization. The first level is ontogenetic and is closely related to the changing social developmental situation. At this level, the consideration of different forms of the individual's participation in sociocultural interactivities and shared meaning-making practices is crucial [Coulter, 1979; Lemke, 1990; Shotter, 1993a]. The second level can be referred to as functional and deals with concrete regularities of knowledge and skill acquisition. In Leont'ev's terminology, it is the level at which transformations of specific actions, rather than activities as certain types of social life, are analyzed. It was this level that received most of Gal'perin's attention. For this reason, the social component of activity was not the focus of Gal'perin's research although it is implicitly present in the very foundation of his theory [Gal'perin, 1976a].

Gal'perin argued that to clarify the process of internalization, i.e., the transformation of initially external activity into its 'internal' form, neither consideration of the communicative aspects of joint activity (addressed by Vygotsky) nor investigation of the powerful impact of material activity on the individual's mental performance (addressed by Leont'ev) is completely sufficient.

[I]t was impossible to clarify what substantive connection existed between mental activity and 'object-related activity' and, consequently, the content of mental activity itself. The difficulty was that the objective content of external activity was conceived as something indisputably non-psychological, whereas the 'true content' of mental activity was considered something nonobjective. This created an insuperable barrier to resolution of the most important question in the 'problem of activity', namely, understanding mental activity itself as being fully substantive, i.e., as being also 'object-related' activity. The conception of mental activity itself continued to remain inaccessible to objective analysis. As a result, the role of external activity in the effectiveness of mental activity and its development was objectively reduced to the position of a system of conditions... Previously it had not been taken into account, but now it was demonstrated that it was necessary to take this system into account. Nevertheless, the external remained external, and the internal remained internal. Even the use of signs as instruments of mental activity and their 'growing from the outside inwards' (i.e., the use of 'for oneself' and 'in one's mind'), without an explanation of what exactly took place in this case or how external activity and its external instruments changed, were unable to alter the former views of mind [Gal'perin, 1977/1992, p. 44].

It was in order to elucidate 'what exactly took place'. i.e., how the concrete operational content of an action gets internalized, that Gal'perin turned to the analysis of the structure and formation of concrete human action. He developed the method of studying the sequential transformations of action from material to mental form, which, he claimed, proved a more adequate instrument of research than mere observation. The 
method itself is fairly well known as the 'stepwise formation of mental actions' [Haenen, 1993; Van Parreren and Carpay, 1980]. According to Gal'perin, mental actions are the key components of psychic functioning. The great advantage of mental actions is that the result can be predicted and presented to the subject before it is physically achieved. It can be tested and evaluated against a given goal. Subsequently, the subject has the possibility of making necessary corrections in advance, before commencing the material action and thus avoiding many vital mistakes. Gal'perin regarded such anticipatory mental orientation and preliminary adjustment of the subject's actions to the everchanging environment as the main function of the psyche [Gal'perin, 1976a, 1980].

Together with images, mental actions constitute the basis for the subject's orienting activity. These components are complementary and inseparable. Mental actions can only be carried out on the basis of images. But new images and concepts are always formed on the basis of actions. In fact, they are themselves nothing else but a simultaneous and automatized form of mental actions [Gal'perin, 1957/1989; Podolskij, 1991]. Consequently, from the microgenetic perspective (i.e., the formation of a concrete image or action), mental actions precede mental images. For this reason, Gal'perin turned to the analysis of mental actions and their genesis. He maintained that mental actions should be conceived as transformed and abbreviated material actions, and he dedicated much of his effort to exploring the concrete regularities, tools, and stages of such transformation. In Wertsch's [1981] view, it is from this perspective that the stepwise procedure, which became the hallmark of Gal'perin's theory, can be considered as an elaboration of Vygotsky's concept of internalization. Yet behind this method are some concepts and distinctions formulated by Gal'perin that are of special interest with respect to the problem of internalization and external/internal activity relationship. Rather paradoxically, Gal'perin spoke about the internalization of human activity and at the same time argued that all mental activity is entirely external. To explain this paradox and to correctly understand Gal'perin's account of internalization and the internal/external relationship, we must consider two important points that are part of his theory. The first can be called the ontological externality of mental activity. The second is related to his distinction between different types of subject's actions.

\section{Externality of Mental Activity}

Gal'perin was speaking about the internalization of initially external action when describing the formation of human mental action [Gal'perin, 1967]. He used the terms 'external speech' and 'internal speech' for different stages of the formation. He meant to emphasize the difference in the form in which an action is performed at the beginning of the stepwise procedure (material, external, or unfolded form of action) and at the end of it (mental, internal, or reduced form of action). Yet he repeatedly claimed that this multimodal transformation of human action does not bring it 'inside' the individual. Even when carried out mentally, the action remains a form of the subject's external activity that deals with problems and tasks of the external world and is irreducible to brain processes:

It is not cerebral processes ... but only the objects and the processes of the external world coded in them that are reflected in the mind. The processes of higher nervous activity and their strictly physiological characteristics are not represented in the "phenomena of consciousness'. Although we say that we have a perceptual image. we do not see an image, but rather the objects represented in it; and 
ons' [Haenen, ctions are the actions is that ally achieved. ibject has the $\mathrm{g}$ the material anticipatory to the evera, 1980]. ect's orienting tions can only lways formed Iltaneous and 991]. Consee image or acturned to the ctions should dicated much h transformase procedure, laboration of concepts and $t$ to the probparadoxically, time argued to correctly relationship, can be called s distinction

action when ed the terms He meant to beginning of at the end of hat this mulvidual. Even rnal activity to brain pro-

4 world coded ir strictly physhough we say nted in it: and processes, but only of some meaning of objective actions represented by the informational content of these processes. If we had wanted to investigate mental activity from the standpoint of the brain (which was the obsessive idea of 'physiological psychology', and is the same for any physiological conception of the relationship between mind and brain), we should have to find a way to record not these neural processes themselves, but indeed the informational content latent in them, in coded form, that expresses the content of some other objective, and consequently mental, activity. But if we were successful in doing this, the informational content of neural processes would, in turn, refer us to what was reflected in it, to the external world and the actions of the subject directed towards getting his bearings in that world, represented in this informational content. Thus, even successful attempts to explain mental activity in the 'depths of the brain' would take us back to the external environment of the subject, to the subject's orientation in the problem situation, and to the purposeful actions conditioned by that orientation [Gal'perin, 1978/1992, p. 68].

In general, Gal'perin's account of the externality of mental activity is closely connected to the concept of external, object-related, meaningful (human) activity, as propounded by Leont'ev. The object relatedness (predmetnost) of the activity is meant to emphasize that meaningful activity is, first of all, actual, productive activity that purposefully transforms the external material into a desired product. To be successful, such activity has to follow the logic and relations of the external objects. It cannot be explained by 'internal' components. On the contrary, the subject's mental processes are shaped by external object-related activity that

changing the environment, also forces the active subject to change. The stubborn facts - what is possible and what is not possible in the purposeful transformation of things - determine mental activity ... external, object-related, meaningful activity thus becomes the genuine foundation of mental development [Gal'perin, 1977/1992, p. 40].

In Leont'ev's works, the main emphasis was on the analysis of the object-related activity as a genetic 'predecessor' of mental activity. Gal'perin took the next important step by viewing mental processes themselves as a form or variation of external object-related activity, carried out by the subject on the basis of mental actions.

Mental processes, in Gal'perin's interpretation, are therefore not internal, psychic faculties, nor are they a reflection of brain processes. They are object-related actions, as all human actions are, the only difference being that mental actions are carried out in a specific form, i.e., without physical execution. Conceptualizing mental activity as a part and a kind of object-related activity implies that it belongs to and occurs in the objective, outer world, as an external process. It is accomplished not according to any internal psychic laws, but according to the laws of the external world. In other words. mental actions, just like all human actions, possess the properties of external objects and processes and are performed in compliance with the specific characteristics of these objects and processes. They have the same objective content as the relevant material actions in a particular field [Arievitch and Stetsenko, 1989].

When we transform a situation physically, say, rearrange the furniture of our room, we have to take into consideration the relevant properties of the things we are acting upon - the size of the room, the size, shape, and weight of certain pieces of furniture - to make sure that everything fits and that we can handle the operation. The properties of objects determine the ways that we act with them. According to Gal'perin, the same holds true when we are merely planning the changes, transforming the situation mentally. Mental actions are directed to and deal with the same external properties of things and have to be in compliance with these physical properties (as well as social conventions if, in addition, we intend to please someone with our rearrangement). Nothing of 
some other, psychic or internal nature is involved in our mental actions, whether we are standing in the center of the room and looking around, i.e., performing the transformations on a perceptual plane, or only imaging them, away from the immediate spot.

More generally, external objects and properties should of course be understood in a broader sense than conveyed in this simple example. The object can be any process or discipline, depending on the problem a subject is confronting. The properties and regularities of a given field determine the content and the very nature of the relevant mental actions. Mathematical calculations or experiments in physics, even when performed mentally, remain mathematical and physical, i.e., are carried out in compliance with the laws of mathematics and physics, rather than psychological or physiological laws.

Gal'perin's belief that subjects' mental actions pertain to and function in the external world found concrete expression in his analysis of the properties of human action. In this analysis he starts not from the subject's internal pecularities but from the properties of action and its content, as described in a relevant objective field (discipline), such as mathematics, physics, or history. Every action is characterized by several fundamental parameters or, as Gal'perin called them, primary properties - the composition of the operational content of action, the extent of differentiation of the relevant elements of the problem situation from the irrelevant ones, level of execution, and several others. From certain combinations of these properties stem the secondary properties of action - the extent to which it can be generalized, the extent to which it is adapted to the objective conditions, and the degree to which the subject can reflect on the action and the way it meets some objective criteria. Both groups of properties represent the objective, socially evaluated qualities of human activity. Detailed discussion of these properties and their evolution in the course of action formation can be found in many of Gal'perin's works [Gal'perin, 1965,1969].

After singling out these properties of action, Gal'perin turned to the scrutiny of the system of conditions that make it possible for the subject to appropriate a certain action. Identifying this system of conditions enabled him to trace the regularities in how action having a given objective content is transformed from the material from into a mental form having the same objective content, thus becoming a psychic process. For example, Gal'perin [1976b/1989] demonstrated how the material form of self-control in primary school children gradually changes into the mental form that we call attention. In the present context, it is important to emphasize that by characterizing an action through object-related parameters and by concretely demonstrating the identity of the objective operational content (predmetnoe soderzhanie) of action during its transformation into mental form, Gal'perin attached external, object-related status to the mental actions that constitute the genuine essence of psyche. He thereby eliminated the Cartesian characteristic of mental actions and the external/internal dichotomy [Gal'perin, 1965, 1976a].

The preceding analysis led Gal'perin [1974/1989] to assert that we need not presume some 'internal' laws that determine mental activity, nor any immanently 'internal' activity as such.

[T]hese references to 'previously unknown capacities' conceal vestiges of pre-scientific notions about mental activity - about 'the active nature of the mind'. which may exist to some extent, but which has no structure (in the scientific sense of the word). and the properties of which can be judged only on the basis of its results. We might say, repeating the words of Laplace, that from the position of the systematic formation of mental actions and concepts. we don't need such a hypothesis. We are speaking about those actions that are learned and that initially function as objective processes subject 
whether we are he transformaiate spot.

understood in any process or rties and regu-elevant mental hen performed liance with the cal laws.

on in the exteruman action. In the properties ipline), such as al fundamental ition of the opelements of the al others. From of action - the o the objective and the way it jective, socially erties and their l'perin's works

the scrutiny of briate a certain ularities in how ial from into a fic process. For self-control in call attention. zing an action identity of the its transformato the mental ated the Cartemy [Gal'perin,

need not preently 'internal'

scientific notions rome extent. but th can be judged in the position of nothesis. We are rucesses subject to 'competent' reproduction at different levels - material, perceptual, verbal, and mental. These actions must also first be learned as external processes, and then ... they are inevitably and lawfully transformed into ideal and, finally, into 'mental' processes in the strict sense [p. 74].

Gal'perin maintained that material activity and speech are not reifications of pure, internal thought, but 'real work' in which a thought itself is born. For example, the paper-and-pencil calculations a child does, Gal'perin claimed, are not just the material fixation of the results of some internal thinking but the activity of thinking itself [Gal'perin, 1965]. In this respect his views are very similar to those of Wittgenstein [1978], who argued that 'when one does calculations with pencil, that is usually all that happens cognitively. There is generally no shadow calculation in the mind accompanying it ... Cognitive processes are immanent in the discursive practices that are right in front of our noses' [p. 154]. Gal'perin's stepwise procedure was designed to concretely analyze how this 'material-born' thought gradually develops into its mental form, thus becoming 'internalized'.

Throughout Gal'perin's writings, we witness how the spatial metaphor of internalization is eliminated and replaced by the conception of different forms of a subject's external activity. Why, then, did Gal'perin retain the terms 'internalization' and 'the internal plane of action' at all? This question brings us to the second (narrower) meaning of Gal'perin's concept of mental action and his elaboration of the different types of actions a subject may perform.

\section{Types of Actions}

When Gal'perin first launched his research program in the early 1950 s, he used the term 'mental actions' (umstvennie dejstvija) as a synonym for psychic actions at large (the same broad sense in which we used it earlier). But as soon as research was extended to different types of psychic actions, he started using for all of these types the more general terms 'ideal action' and 'ideal plane of action'. By ideal actions he meant actions that are performed and in which the result is achieved 'in the mind', mentally, 'ideally', i.e., without or before physical execution (and without speech), on the 'ideal' plane. In this sense, an ideal action and the ideal plane of action are contrasted with a material action that transforms the situation physically. Thereby, in the context of different types of ideal actions, the meaning of the term 'mental action' was narrowed and retained for only one type of ideal action. This narrower meaning of mental action looms in the preceding [1974/1989] quotation in which Gal'perin speaks about the transformation of an action 'into ideal and, finally, into "mental" processes in the strict sense'. The specificity of these mental actions 'in the strict sense' among other types of actions clarifies Gal'perin's account of internalization.

Gal'perin distinguished between three basic action types - physical, mental, and perceptual. A fourth and somewhat special type not discussed here is verbal action carried out on the plane of social consciousness [Gal'perin, 1965]. The distinctions are grounded in the peculiarities of transformations that actions undergo in the course of their formation, specifically whether they become internalized at the level or plane they are executed on - material. ideal external, or ideal internal. Thus it is with respect to types of actions that we encounter the external/internal opposition and the term 'internal plane of action' in Gal'perin's works. Given Gal'perin's view regarding the overall externality of mental activity, we can assume that he emploved the term 
'internal' in other than the conventional sense. In other words, he in no way implied the meaning 'within the individual or the brain'. Instead, Gal'perin meant by 'internal' the subject's ability to perform a certain action without the immediately present problem situation, 'in the mind', and to act with nonsensory as well as sensory characteristics of objects. The lack of such an ability - the boundedness of a certain action to the physically and perceptually present situation and the perceived properties of objects-denotes that' an action remains external, 'physical object-dependent', i.e., it is not (or cannot in principle be) 'internalized' [Gal'perin, 1965]. Returning to the example of room redesign, in Gal'perin's terms the mental rearrangement of furniture by the subject while he or she is away from the room is an instance of an internal action or an action performed on the internal plane. But if the subject is planning the changes right on the spot, visually or materially, or if moreover, it is difficult or impossible for him or her to properly do so 'in the mind', i.e., outside that room, the instance is one of external action.

In this sense, according to Gal'perin, both physical and perceptual actions remain external, i.e., they do not become internalized in the course of their formation. The difference between them is that physical actions are performed materially, in the plane of material objects and cause material changes, whereas perceptual actions are executed in the 'ideal' plane, i.e., without material consequences. But these ideal perceptual actions (as well as their result - a certain sensory image) are, in Gal'perin's interpretation, also external - because the subject is carrying out actions in a problem situation that is visually displayed. In Gal'perin's [1957/1989] words, 'the formation of a sensory image basically takes place in the same way [as the formation of a mental action and image], only in this case an action, since it is ideal, is not transformed into a mental action, but remains within perception' [p. 62].

According to Gal'perin, mental actions thus 'in the strict sense' are those performed on the basis of mental representation, i.e., independently of the physical presence of things. As perceptual actions, they are also a kind of ideal action, in the sense that they do not materially transform the situation. But unlike perceptual actions, mental actions do not 'remain within perception'. They are carried out on the 'internal' plane (in the internalized form), without being anchored to the actual display of the problem situation. In other words, they are the only type of action that becomes entirely internalized in the course of its appropriation.

It is thus only in the formation of mental actions that appropriation, as the general process of some new acquisition of activity by the subject, and internalization. as a special type of such acquisition, coincide. With respect to other types of actions, there is no such coincidence, i.e., appropriation does not necessarily imply internalization. When a subject is learning some new physical actions (e.g., in sport or labor), the execution of these actions remains on the material level (plane) even when they are already appropriated. The appropriation of perceptual actions (e.g., operations of monitoring by airtraffic controllers) by the subject results in the formation of an ideal form of action but the execution of those actions nevertheless remains external, within the perception of the displayed situation. In Gal'perin's $[1965,1967]$ view, only when the appropriation of a new action leads to the formation of mental action. can one speak about internalization of this action.

We can now finally formulate Gal'perin's concept of internalization succinctly. Internalization is a specific type of appropriation of new actions involving the formation of mental actions; these are conceived of as an execution of actions independently of the material presence of a problem situation. In other words. internalization can be viewed 
$y$ implied the 'internal' the sent problem racteristics of to the physiects-denotes (or cannot in f room redebject while he on performed spot, visually roperly do so

ctions remain tion. The difthe plane of e executed in eptual actions retation, also n that is visuy image basiimage], only ction, but re-

e those perphysical presin the sense ctions, men'internal' lay of the mes entirely

s the general ion. as a speis, there is no tion. When a execution of ready approoring by airof action but perception of ropriation of t internaliza-

in succinctly. he formation dently of the in be viewed as a subject's transition from 'physical object-dependent' problem solving to 'physical object-independent' problem solving. Gal'perin's planes (levels) of action - the material plane (with the dependence of action on the material manipulation with objects), the perceptual plane (without material manipulation but with the dependence of an action on the perception of material objects), and the mental plane (independent of the actual presence of material objects) - represent the increasing flexibility of actions, allowing new possibilities for the subject.

It is important to note again that in the described context the 'internality' of mental actions does not mean 'within the individual' or 'in the brain', but solely the possibility of the subject's performing actions when separated from the physically and sensorially presented field of action. This view corresponds to the general conception of the opensystemic nature of development in which both 'internality' and 'externality' of activity become reflections of the process of person-environment exchange [Valsiner, 1987; 1993].

We can now return to the question posed at the beginning of this article as to why we think that the meaning of the concept of internalization is not yet exhausted in the continuing discussion of its value in modern psychology. Gal'perin's answer to this question is related to the specificity of human mental development and the formation of the mental plane of actions. Unlike appropriation or mastery, internalization refers to the specifically human ability to operate on the internal plane. It is clear that for Gal'perin, the concept of an 'ideal' action is broader than the concept of a 'mental' action. He maintained that the ideal plane of action, i.e., some forms of psychic activity, can be observed in animals as well, but it is only in humans that the mental plane of actions is formed. According to Gal'perin [1965], internalization as a specific kind of appropriation is inherent only in humans. In other words, animals do acquire ideal (psychic) actions, but these actions never get internalized, i.e., abstracted from the physical objects. All forms of animals' psychic activity, such as thinking, memory and so on, remain within the realm of perception and do not constitute the 'hierarchical structure of consciousness' [Vygotsky, 1978] typical of humans. Thus, in problem solving. animals are always restricted to (dependent on) the visually presented situation and can never transcend its perceptual characteristics [Köhler, 1927]. Only humans can act independently of the perceived situation - 'in mind' or 'internally'.

To this peculiarity of human mental activity, another is closely tied - the ability to operate with nonvisible and moreover with nonsensory properties of objects. The orientation to properties that are not visible and cannot be sensed before physical action (e.g., weight) or cannot be directly perceived at all but merely judged (e.g., mechanical regularities) is excessively difficult even for the most intelligent apes. Gal'perin 's [1965] explanation of this fact amounts to his belief that it is only human speech (due to its semiotic character, forged in social meaning-making practices) that makes it possible to go beyond perception and to abstract an action from the physically displayed situation, thereby creating the possibility for internalization and the formation of the internal plane of action [Vygotsky, forthcoming]. In Gal'perin's empirical work, concrete ways of internalization and formation of the internal plane of action were scrutinized in scores of experiments. He appears to have been the first within sociocultural psychology to demonstrate the acquisition of the operational content of human activity [Gal'perin. 1965, Haenen, 1993]. 


\section{Summary and Conclusions}

In this article we have described Gal'perin's perspective on the problem of internalization in the framework of his conceptualization of the relationship between external and internal activity. Our effort was prompted by recent critiques of the concept of internalization. We share the basic concerns expressed by Wertsch [1993], Rogoff [1990]. and others. The concept of internalization may lead to interpretations that reintroduce old pitfalls in psychology - individualistic and dualistic perspectives regarding the starting points of mental development. The temptation to replace internalization with more neutral concepts such as appropriation or mastery is understandable. In doing so, however, we may lose sight of some specific features of human mental development, such as the formation of the internal plane of consciousness.

As we have tried to demonstrate, Gal'perin's theory of the formation of mental activity exemplifies how the concepts of internalization and internal activity can be construed without falling into Cartesian dualism. His theory provides the understanding of mental processes as different forms of external activity. Whereas Leont'ev's main emphasis was the analysis of object-related activity as a genetic predecessor of mental activity, Gal'perin took the next important step by viewing mental processes themselves as a form or variation of external object-related activity carried out by the subject on the basis of ideal actions.

In Gal'perin's interpretation, mental processes are not internal, psychic faculties, nor are they a reflection of brain processes. Like all human actions, they are external object-related actions, the only difference being that ideal actions are carried out in a specific form, i.e., without physical execution, on the ideal plane. But this difference does not make them internal. These actions are formed and function as part of the subject's external activity and in accordance with the laws and relations of external objects in a certain realm of the subject's activity. These laws and relations determine all of the particular properties and the whole objective content of ideal (psychic) actions. No psychic activity is occurring within the individual and no shadow internal processes accompany the external realization of the relevant objective content. In Gal'perin's view, such an interpretation leaves no room for dualistic implications about psychic activity.

Within psychic activity, Gal'perin distinguished a specifically human type of action - mental action performed on the so-called internal plane, i.e., independently of the physical presence of the problem situation. Internalization in this framework is viewed as the formation of the internal plane of action. Like Gal'perin's general account of psychic activity, his concepts of the internal plane of action and internalization imply neither the meaning 'within the individual' nor any presumptions about internal copies of external processes. Rather, these concepts imply the transformation of certain forms of human external activity (with certain possibilities for the individual) into other forms (with other possibilities) and reflect a new level of flexibility in performing certain actions, one that emerges only in humans. Compared to appropriation and mastery, internalization more explicitly refers to the formation of the human ability to operate with nonsensory properties of objects and not be tied to the visually displayed situation (due to the semiotic character of all human activities)

In conclusion, it is not the term 'internalization' itself that we are trying to salvage. Rather, our concern is the exhaustive analysis of the content that underlies it. Although the concept of internalization can cause dualistic confusion, it emphasizes the specific character of human mental processes. Further analysis is necessary to fully realize its 
em of inter-

tween exter-

e concept of ogoff [1990] reintroduce ng the startwith more ing so, hownent, such as

f mental accan be conrstanding of 's main emf mental acemselves as bject on the

hic faculties, external obout in a speerence does the subject's objects in a 1 of the parNo psychic accompany iew, such an

pe of action ently of the $\mathrm{rk}$ is viewed account of ation imply ernal copies ertain forms other forms certain acastery, interperate with uation (due

to salvage. t. Although the specific realize its value in this respect, before any other more adequate term can be advanced that captures the processes and distinctions identified by Gal'perin. Such an analysis would be an important contribution to the account of the social construction of the human mind.

\section{Acknowledgments}

We are grateful for the valuable comments of Anna Stetsenko and three anonymous reviewers. The writing of this article was supported by a grant from the Nederlandse Organisatie voor Wetenschappelijk Onderzoek (NWO) awarded to the first author.

\section{References}

Aaronfreed. 1. (1968). Conduct and conscience: The socialization of internalized behavior. New York: Academic Press.

Arievitch, 1., \& Stetsenko, A. (1989). From Vygotsky to Gal'perin: Development of an idea of mental action's externality. Storia e critica della psicologia, $1,111-113$.

Baldwin. J. M. (1911). Thought and things. A study of the development and meaning of thought, or genetic logic: Vol. 3. Interest and art. London: George Allen.

Bandura, A. (1986). Social foundations of thought and action: A social cognitive theory. Engelwood Cliffs NJ: Prentice-Hall.

Bruner, J. S. (1990). Acts of meaning. Cambridge MA: Harvard University Press.

Bibler. K. (1930). The mental development of the child New York: Harcourt Brace.

Claparède, E. (1931). L'éducation fonctionelle, [Functional education]. Neuchatel: Delachaux \& Niestlé.

Cole, M. (1979-1980). Introduction: The Khar'kov school of developmental psychology. Soviet Psychology, 18 (2), 3-8.

Coulter, J. (1979). The social construction of mind: Studies in ethnomethodology and linguistic philosophy. London: Macmillan.

Davydov, V. V. (1993). The perspectives of activity theory. Multidisciplinary Newsletter for Activity Theory, 13/14, 50-53. Durkheim. E. (1912/1985). Les formes élémentaires de la vie religieuse: Le systéme totémique en Australie [Elementary forms of religious life: Totemic system in Australia). Paris: Quadrige/PUF.

Engeström. Y. (1991). Activity theory and individual and social transformation. Multidisciplinary Newsietter for Activity Theary, 7/8, 6-17.

Gal'perin. P. Ya. (1957/1989). Mental actions as basis for the formation of thoughts and images. Soviet Psychology, 27 (3), 45-65.

Gal'perin. P. Ya. (1965). Osnovnye resultaty issledovanij po probleme 'Formirovanie umstvennykh dejstvij i ponjatij' [Fundamental results from the investigation of the problem of 'the formation of mental actions and concepts']. Doctoral dissertation, University of Moscow.

Gal'perin. P. Ya. (1967). On the notion of internalization. Soviet Psychology, 5 (3), 28-33.

Gal'perin. P. Ya. (1969). Stages in the development of mental acts. In M. Cole \& I. Maltzman (Eds.), A handbook of contemporary Soviet psychology (pp. 249-273). New York: Basic Books.

Gal'perin. P. Ya. (1974/1989). Organization of mental activity and the effectiveness of learning. Soviet Psychology, 27 (3). 65-82.

Gal'perin. P. Ya. (1976a). Vvedenie v. psikhologiju [Introduction to psychology]. Moscow: Moscow University Press.

Gal'perin. P. Ya. (1976b/1989). The problem of attention. Soviet Psychology, 27 (3), 83-92.

Gal'perin. P. Ya. (1977/1992). The problem of activity in Soviet psychology. Journal of Russian and East European Psychology, 30 (4). $37-59$.

Gal'perin. P. Ya. (1978/1992). Stage-by-stage formation as a method of psychological investigation. Journal of Russian and East European Psychology, 30 (4), 60-80.

Gal'perin. P. Ya. (1980). The role of orientation in thought. Soviet Psychology, 18 (2), 84-99.

Haenen, J. (1993). Piotr Gal'perin: His lifelong quest for the content of psychology. Doctoral dissertation, University of Amsterdam.

Harré, R. (1983). Personal being: A theory for individual psychology Oxford: Blackwell Publishers

Harré, R. (1992). Introduction: The second cognitive revolution. American Behavioral Scientist, 36, 5-7.

Janet, P. (1928). L'evolution de la mémoire et la notion tu temps [Evolution of memory and the notion of time]. Paris Maloine.

Janet. P. (1935). Les déburs de lintelligence [The origins of intelligence]. Paris: Flammarion.

Köhler, W. (1972). The meutality of the great apes. London: Kegan Paul.

Kozulin. A. (1986). The concept of activity in Soviet psychology: Vygotsky. his disciples and critics. American Psy. chologist, 41 (3) . 264-27-

Lave, J. \& Wenger. E. (1991). Situated learning: Legitimate peripheral participation. New York: Cambridge University Press. 
Lawrence, J., \& Valsiner, J. (1993). Conceptual roots of internalization: From transition to transformation. Human Development, 36 (3), 150-167.

Lemke, J. L. (1990). Talking science; Language, learning and values. Norwood NJ: Ablex.

Leoni'ev A. N. (1959/1981). Problems of the development of mind. Moscow: Progress.

Leont'ev, A. N. (1978). Activity, consciousness and personality. Englewood Cliffs NJ: Prentice Hall.

Lévy-Bruhl, L. (1922). La mentaliné primitive [The primitive mentality]. Paris: Retz.

Luria. A. R. (1979). The making of mind. Cambridge MA: Harvard University Press.

Markovà, 1. (1982). Paradigms, thought and language. New York: Wiley.

Markova, I. \& Foppa, K. (Eds) (1990). The dynamics of dialogue. London: Harvester Wheatsheaf

Mead, G. H. (1934). Mind, self, and society. Chicago: Chicago University Press.

Newmian, D. Griffin, P. \& Cole, M. (1989). The construction zone. New York: Cambridge University Press.

Piaget, J. (1974). The child and reality: Problems of generic psychology. London: Frederick Muller.

Podolskij, A. 1. (1991). New life of old idea: Process of internalization as we see it in learning experiments and instructional practice. Invited address at the 4th EARLI Conference, Helsinki.

Ratner, C. (1991). Vygotsky's sociohistorical psychology and its contemporary applications. New York: Plenum.

Rogoff, B. (1990). Apprenticeship in thinking: Cognitive development int social context. New York: Oxford University Press.

Shotter, J. (1993a). Vygotsky: The social negotiation of semiotic mediation. New Ideas in Psychology. 1I, 61-75.

Shotter, J. (1993b). Bakhtin and Vygotsky: Internalization as a boundary phenomenon. New Ideas in Psychology, II. 379-390.

Still. A. \& Costall, A. (1991). The mutual elimination of dualism in Vygotsky and Gibson. In A. Still \& A. Costal (Eds). Against cognitivism: Alternative foundations for cognitive psychology (pp. 225-236). Hemel Hempstead: Harvester Wheatsheaf.

Tolman, C. W. (1992). Neopositivism and pereeption theory. In C. W. Tolman (Ed.), Positivism in psychology. New York: Springer.

Tudge. J. R. H., \& Winterhoff. P. A. (1993). Vygotsky, Piaget, Bandura: Perspectives on the relations between the social world and cognitive development. Human Development, 36, 61-81.

Valsiner. J. (1987). Culture and the development of children's action. Chichester: Wiley.

Valsiner, J. (1993). Making of the future: Temporality and the constructive nature of human development. In G. Turkewitz \& D. A. Devenny (Eds.), Developmental time and timing (pp. 13-40). Hillsdale NJ: Erlbaum.

van der Veer. R., \& Valsiner, J. (1991a). Understanding Vygotsky: A quest for synthesis. Oxford: Blackwell.

van der Veer, R., \& Valsiner. J. (1991b). Sociogenetic perspectives in the work of Pierre Janet. Storia della psicologia. 3. 6-23.

van der Veer, R., \& Valsiner, J. (Eds.) (1994). The Vygotsky reader. Oxford: Blackwell.

van Geert, P. (1987). The structure of Gal'perin's model of the formation of mental acts: A generative approach. Human Development, 30, 355-381.

van Parreren, C. F., \& Carpay. C. A. (1980). Sovjetpsychologen over onderwijs en cognitieve ontwikkeling [Soviet psychologists on education and cognitive development]. Groningen: Wolters-Noordhoff

Vygotsky, L. S. (1930/1981). The instrumental method in psychology. In J. V. Wertsch (Ed.). The concept of activity in Soviet psychology (pp. 134-143). Armonk NY: Sharpe.

Vygotsky. L. S. (1978). Mind in society. Cambridge MA: MIT Press

Vygotsky. L. S. (forthcoming). Preface to Köhler. In R. Rieber \& A. S. Carton (Eds.). The collected works of L.S. Vygotsky: Vol. 3. Problems of the theory and history of psychology. New York: Plenum.

Vygotsky. L. S. \& Luria. A. R. (1930/1993). Essays on the history of behaviour: Ape, primitive, and child. Hillsdale NJ: Erlbaum

Wertsch. J. V. (1985). Vygotsky and the social formation of mind. Cambridge MA: Harvard University Press.

Wertsch. J. V. (1981). Trends in Soviet cognitive psychology. Storia e critica della psicologia. 2 (2), 219-295.

Wertsch. J. V. (1993). Commentary. Human Development, 36 (3), 168-171.

Wertsch. J. V.. \& Stone. C. A. (1985). The concept of internalization in Vygotsky's account of the genesis of higher mental functions. In J.V. Wertsch (Ed.). Culture, communication and cognition: Vygotskian perspectives (pp. 162-179). Cambridge MA: Harvard University Press.

Wittgenstein. L. (1978). Philosophical investigations. Oxford: Blackwell.

Igor Arieviteh. Department of Developmental Psychology, Institute of Psychology. University of Bern. Uni-Tobler. Muesmattstrasse 45. CH-3000 Bern (Switzerland) 